\title{
Potensi pencemaran air tanah bebas pada sebagian kawasan resapan air di Lereng Selatan Gunung Api Merapi
}

\author{
Sadewa Purba Sejati* \\ * Program Studi Geografi, Fakultas Sains dan Teknologi, Universitas Amikom \\ Yogyakarta, Indonesia
}

\begin{tabular}{l}
\hline \hline INFO ARTIKEL \\
\hline Riwayat Artikel: \\
Dikirim: $20-6-2019$ \\
Disetujui: 4-11-2019 \\
Diterbitkan: $30-1-2020$
\end{tabular}

Kata kunci: potensi pencemaran; air tanah bebas; GOD

\begin{abstract}
ABSTRAK
Decreasing quality of unconfined groundwater is one of the impacts which may occur as increasing number ofpopulation as a consequence of the development in a part of primary water infiltration. Study about the potential of unconfined groundwater pollution needs to be conducted as an alternative for monitoring water quality. Based on GOD method, all confined groundwater areas in the research location is in the high potential of pollution. The condition occurs because the natural factors in the form of aquifer, aeration zone constituent material, and the depth of groundwater have the potential to facilitate interaction between pollutants or pollutant sources with the unconfined groundwater. Variation of groundwater pollution is obtained by developing GOD method, which is by adding a modifier parameter in the form of population density. Development of GOD method results in two classes of the potential of unconfined groundwater pollution, namely the potential for low pollution with an area coverage of $30.6 \%$ of the total area of the study area, and the potential for high groundwater pollution with an area coverage of $69.4 \%$.
\end{abstract}

Penurunan kualitas air tanah bebas merupakan salah satu dampak yang dikhawatirkan akan muncul seiring dengan meningkatnya kepadatan penduduk sebagai konsekuensi dari pesatnya pembangunan yang terjadi pada sebagain kawasan resapan air primer. Kajian mengenai potensi pencemaran air tanah bebas perlu dilakukan sebagai alternatif pematauan kualitas air. Berdasarkan metode GOD, seluruh air tanah bebas di daerah penelitian berada dalam potensi pencemaran sangat tinggi. Keadaan tersebut terjadi karena faktor keadaan alami berupa jenis akuifer, material penyusun zona aerasi, dan kedalaman muka air tanah berpotensi mempermudah interaksi antara polutan atau sumber pencemar dengan air tanah bebas. Variasi potensi pencemaran air tanah diperoleh dengan mengembangkan metode GOD, yaitu menambahkan parameter modifikator yang berupa kepadatan penduduk. Pengembangan metode GOD tersebut menghasilkan dua kelas potensi pencemaran air tanah bebas, yaitu potensi pencemaran rendah dengan cakupan wilayah sebesar $30,6 \%$ dari keseluruhan luas daerah penelitian, dan potensi pencemaran air tanah tinggi dengan cakupan wilayah sebesar $69,4 \%$.

This is an open access article under the CC-BY-SA license

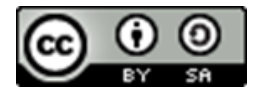

Penulis Korespondensi:

Sadewa Purba Sejati

Program Studi Geografi

Universitas Amikom

Jl. Ring Road Utara, Ngringin, Condongcatur, Daerah Istimewa Yogyakarta 55281

E-mail: sadewa@amikom.ac.id 


\section{PENDAHULUAN}

Kawasan resapan air merupakan suatu wilayah yang secara alami berfungsi sebagai penyimpan dan penyuplai cadangan air tanah bagi wilayah di sekitarnya (Dharoko, 2006 dan Hendrayana, 2013). Kuantitas dan kualitas cadangan air tanah sangat ditentukan oleh kinerja kawasan resapan air. Dewasa ini, pembangunan fisik yang dilakukan berpotensi menimbulkan gangguan pada kinerja kawasan resapan air. Arah atau pola pembangunan perlahan-lahan mulai masuk ke dalam kawasan resapan air. Luasan lahan yang pada awalnya digunakan untuk kepentingan agraris perlahan-lahan berkurang dan berubah menjadi lahan terbangun, seperti pemukiman, pertokoan, pusat pelayanan pemerintah, dan bangunan fisik lainnya.

Kecamatan Ngemplak merupakan salah satu wilayah administratif yang berada di lereng selatan Gunung Api Merapi. Tinjauan dari sudut pandang hidrologi dan geomorfologi menyebutkan bahwa wilayah tersebut berfungsi sebagai salah satu kawasan resapan air primer yang terletak di lereng selatan Gunung Api Merapi (Dharoko, 2006 dan Hendrayana, 2013).

Tidak hanya itu, Kecamatan Ngemplak juga merupakan salah satu wilayah administratif di Kabupaten Sleman yang mengalami dampak dari pesatnya pembangunan. Perubahan penggunaan lahan banyak dijumpai di wilayah tersebut sebagai akibat dari perluasan pola dan arah pembangunan yang terjadi di wilayah Kecamatan Depok (D. Imam, 2013). Fungsi ruang sebagai peresap air hujan pun mengalami penurunan akibat alih fungsi lahan tersebut.

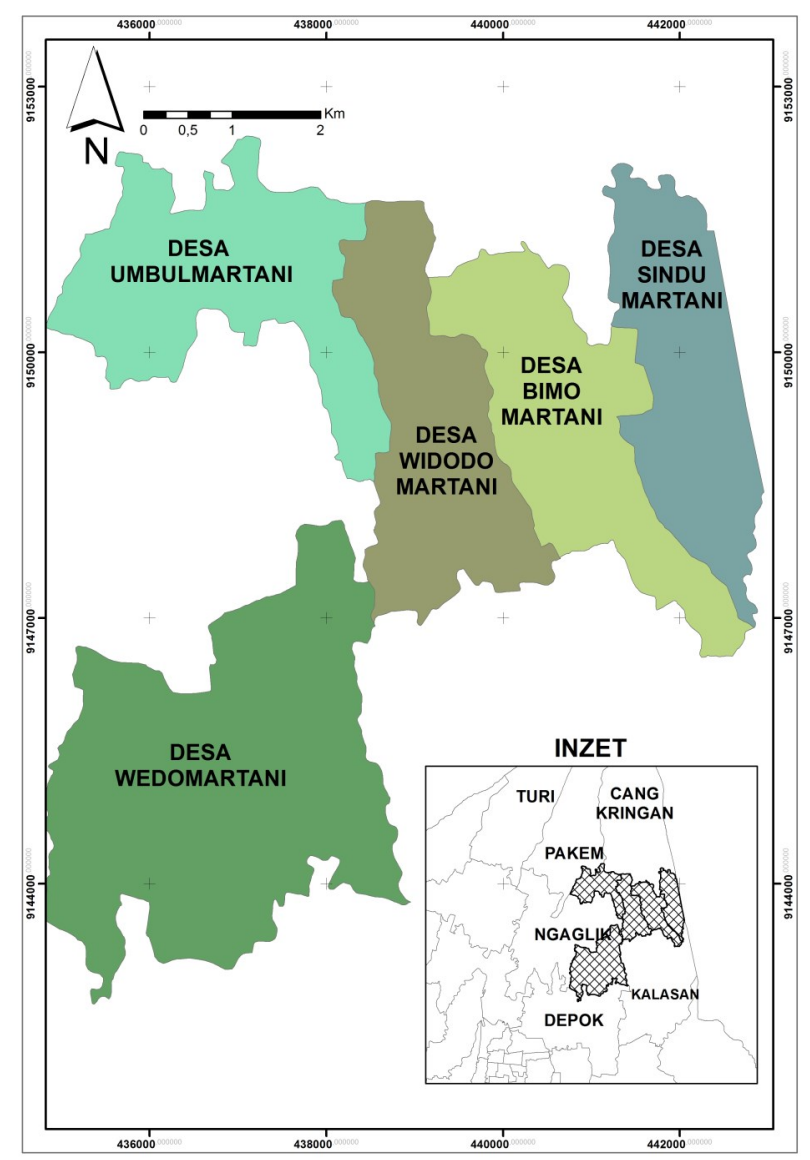

Gambar 1. Peta Administrasi Kecamatan Ngemplak sebagai Daerah Penelitian 
Jurnal Pendidikan Geografi:

Kajian, Teori, dan Praktik dalam Bidang Pendidikan dan Ilmu Geografi

Volume 25, Nomor 1, Jan 2020, Hal 25-38

Pembangunan pada hakikatnya memang bertujuan untuk menciptakan kesejahteraan dan kemajuan masyarakat dalam berbagai bidang. Terlihatnya beragam bangunan fisik dan masifnya kegiatan ekonomi dapat dijadikan sebagai salah satu tanda bahwa kesejahteraan masyarakat mulai terbentuk di wilayah tersebut. Namun demikian, pembangunan seringkali menyembunyikan dampak negatif yang mungkin hanya akan dirasakan oleh generasi mendatang. Penurunan kualitas air tanah bebas merupakan salah satu dampak yang dikhawatirkan akan muncul di Kecamatan Ngemplak seiring dengan pembangunan yang terus terjadi. Bertambahnya kepadatan penduduk merupakan salah satu konsukuensi yang terjadi seiring dengan semakin masifnya pembangunan di suatu wilayah. Aktivitas yang dilakukan oleh penduduk berpotensi mengganggu kualitas air tanah bebas yang berada di bawah permukaan tanah (Sutardi, 2017). Kajian mengenai potensi pencemaran air tanah bebas perlu dilakukan. Hasil kajian ini diharapkan dapat dijadikan sebagai alternatif dasar pematauan kualitas air tanah di daerah penelitian.

\section{METODE}

Penelitian ini dilakukan di wilayah administrasi Kecamatan Ngemplak, Kabupaten Sleman. Daerah penelitian dibatasi dengan koordinat UTM $434000 \mathrm{mT}$ hingga 444000 mT dan 9142000 mU hingga 9152000 mU. Kecamatan Ngemplak dipilih sebagai daerah penelitian karena berdasarkan tinjauan morfologi dan hidrologi termasuk dalam kawasan resapan air di lereng selatan Gunung Api Merapi yang berpotensi mengalami gangguan lingkungan akibat semakin pesatnya pembangunan.

Dua jenis data geospasial digunakan dalam penelitian ini, yaitu data primer dan data sekunder. Data primer berupa data kedalaman muka air tanah bebas. Data tersebut diperoleh dengan cara melakukan pengukuran terdahap kedalaman sumur hingga menyentuh muka air tanah bebas. Sampel sumur yang dijadikan sebagai lokasi pengukuran ditentukan dengan metode systematic random sampling. Untuk mengaplikasikan metode tersebut, terlebih dahulu peta daerah penelitian dibagi berdasarkan grid, ukuran grid adalah $750 \mathrm{~m}^{2}$. Dalam setiap grid yang telah terbentuk, sampel sumur kemudian ditentukan secara acak. Peralatan yang digunakan untuk mengumpulkan data kedalaman muka air tanah adalah meteran ukur dan GPS receiver dengan tipe Garmin $64 \mathrm{~S}$ untuk mencatat posisi koordinat sampel. Selain menggunakan data primer, penelitian ini juga menggunakan data sekunder. Data sekunder yang digunakan adalah Peta Rupabumi Indonesia Lembar Pakem dan Kaliurang dengan skala 1: 25.000 yang dibuat oleh Badan Informasi Geospasial, Peta Geologi Lembar Yogyakarta skala 1: 100.000, data profil stratigrafi material di bawah permukaan tanah,

Tabel 1. Rincian Data Penelitian

\begin{tabular}{|c|c|c|c|c|}
\hline & $\begin{array}{l}\text { Jenis } \\
\text { Data }\end{array}$ & Bentuk Data & Sumber Data & Fungsi Data \\
\hline 1. & Primer & Kedalaman muka air tanah & Pengukuran langsung & $\begin{array}{l}\text { Mengetahui kedalaman muka air } \\
\text { tanah }\end{array}$ \\
\hline 2. & Sekunder & $\begin{array}{l}\text { Peta Geologi Lembar } \\
\text { Yogyakarta skala 1: } 100.000\end{array}$ & $\begin{array}{l}\text { Kemeterian Energi dan } \\
\text { Sumberdaya Mineral }\end{array}$ & Mengetahui jenis akuifer \\
\hline 3. & Sekunder & $\begin{array}{l}\text { Data profil stratigrafi material } \\
\text { di bawah permukaan tanah }\end{array}$ & $\begin{array}{l}\text { PPAB Kementerian } \\
\text { Pekerjaan Umum }\end{array}$ & $\begin{array}{l}\text { Mengetahui material penyusun } \\
\text { zona tidak jenuh air tanah (zona } \\
\text { aerasi) }\end{array}$ \\
\hline 4. & Sekunder & $\begin{array}{l}\text { Jumlah penduduk dan luas } \\
\text { wilayah }\end{array}$ & Badan Pusat Statistik & $\begin{array}{l}\text { Mengetahui karakteristik kepadatan } \\
\text { penduduk }\end{array}$ \\
\hline 5. & Sekunder & $\begin{array}{l}\text { Peta RBI Lembar Pakem dan } \\
\text { Kaliurang Skala 1: } 25000\end{array}$ & $\begin{array}{l}\text { Badan Informasi } \\
\text { Geospasial }\end{array}$ & Membatasi daerah penelitian \\
\hline
\end{tabular}


Jurnal Pendidikan Geografi:

Kajian, Teori, dan Praktik dalam Bidang Pendidikan dan Ilmu Geografi

Volume 25, Nomor 1, Jan 2020, Hal 25-38

dan data kepadatan penduduk. Rincian jenis data, bentuk data, sumber, dan fungsinya dapat dilihat pada Tabel 1.

Potensi pencemaran air tanah bebas secara teoritis dapat dianalisis menggunakan karakteristik fisik alami suatu wilayah. GOD merupakan metode penentuan potensi pencemaran air tanah yang hanya mempertimbangkan parameter fisik alami, yaitu jenis akuifer, kedalaman muka air tanah, dan material zona tidak jenuh air tanah (Vrba dan Zoporozec, 1994; Khemiri, 2013; Abdelmadjid, 2013; Knouz, 2017; Oni, 2017). Nama GOD meruupakan akronim atau singkatan dari parameter-parameter penentu potensi pencemaran air tanah pada metode tersebut, yaitu groundwater occurence (jenis akuifer), overlying strata (material pada zona tidak jenuh air tanah), dan depth of watertable (kedalaman muka air tanah). Informasi mengenai klasifikasi zonasi potensi pencemaran air tanah di suatu wilayah dapat diketahui secara cepat menggunakan metode ini (Hastuti, 2016). Namun demikian, dalam peneiltian ini penulis menganggap bahwa potensi pencemaran di suatu wilayah tidak hanya dipengaruhi oleh karakteristik fisik alami, sehingga penulis mengembangkan metode GOD dengan cara mengkombinasikannya dengan parameter non fisik yang berupa kepadatan penduduk.

Kepadatan penduduk digunakan sebagai parameter tambahan. Asumsi yang digunakan adalah bahwa semakin padat penduduk di suatu wilayah maka potensi sumber pencemar air tanah yang dihasilkannya pun semakin banyak. Potensi sumber pencemar

Gambar 2. Diagram Alir Penelitian

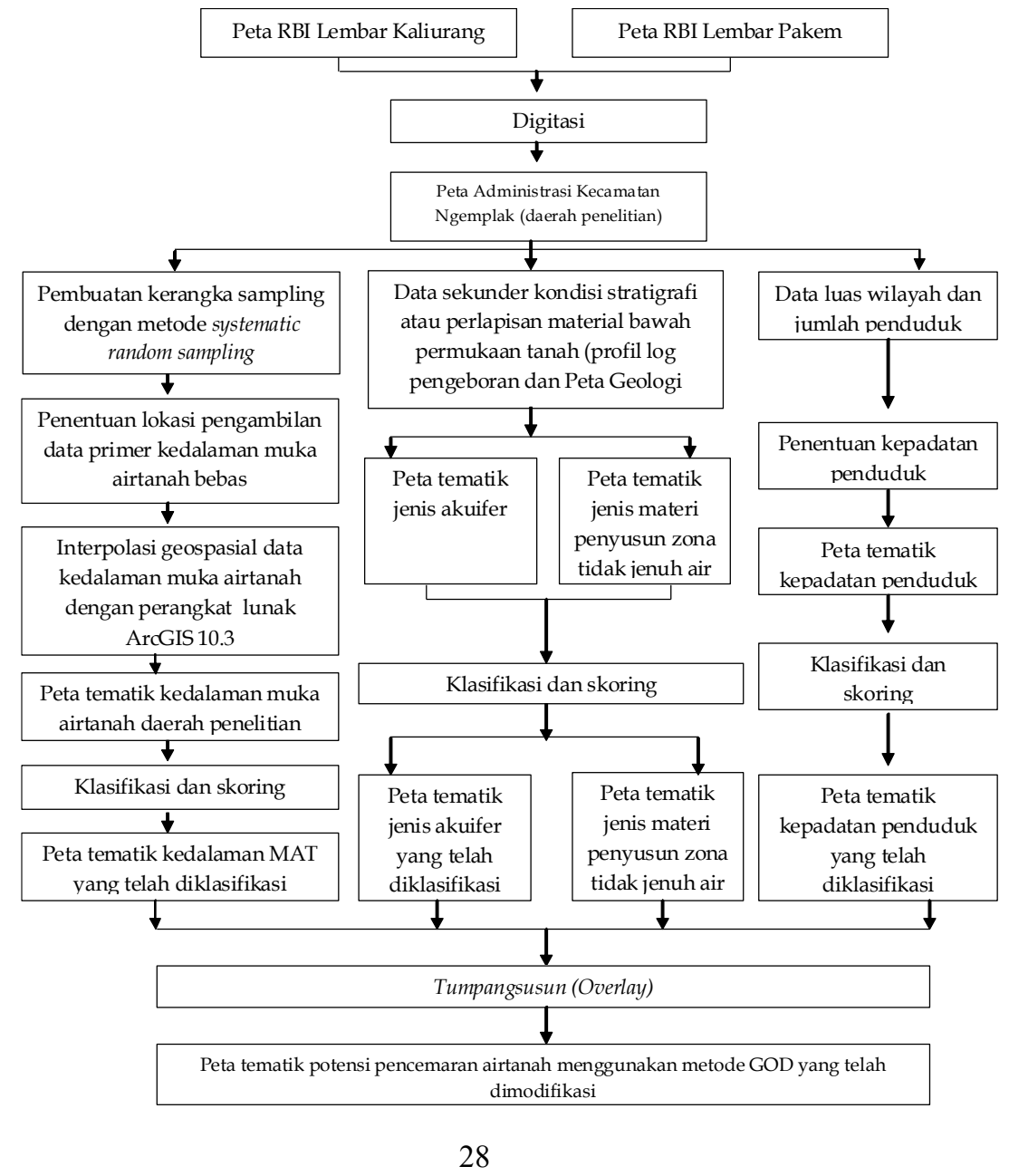


tersebut misalnya berasal dari limbah domestik atau limbah rumah tangga. Untuk mengetahui potensi pencemaran air tanah, setiap parameter yang telah teridentifikasi kemudian diberikan skor. Pemberian skor untuk parameter fisik alami mengacu pada sitem skoring metode GOD (Vrba dan Zoporozec dalam Hastuti, 2016). Untuk parameter non alami berupa kepadatan penduduk, penulis mengkalsifikasikannya menjadi tiga kelas dengan penentuan kelas interval teratur berdasarkan Metode Strurgess, yaitu kepadatan rendah, kepadatan sedang, dan kepadatan tinggi. Masing-masing kelas kepadatan penduduk tersebut diberikan skor mulai dari 0,2 hingga 0,6. Setiap parameter penentu potensi pencemaran air tanah disajikan dalam bentuk informasi spasial yang berwujud peta tematik. Setiap peta tersebut kemudian menjadi masukan dalam analisis data spasial overlay (tumpangsusun). Teknik tumpangsusun dilakukkan dengan perangkat lunak Arc GIS 10.3. Operasi matematika yang digunakan dalam proses tersebut adalah perkalian, dimana setiap skor yang melekat pada setiap parameter penentu potensi pencemaran air tanah dikalikan satu sama lain. Skor hasil akhir kemudian diklasifikasikan untuk mengetahui variasi atau pola keruangan potensi pencemaran air tanah di daerah penelitian. Diagram alir penelitian dapat dilihat pada Gambar 2.

\section{HASIL DAN PEMBAHASAN}

Karakteristik kondisi alami dan non alami suatu wilayah dapat digunakan sebagai parameter untuk menentukan potensi pencemaran air tanah. Dalam suatu wilayah, pola keruangan karakteristik kondisi alami dan non alami tersebut bisa saja mengalami perbedaan. Perbedaan tersebut muncul karena variasi kondisi topografi, kondisi geologi, dan kondisi sosial ekonominya. Sebelum potensi pencemaran air tanah ditentukan, persebaran spasial atau pola keruangan setiap parameter yang akan digunakan untuk menentukan potensi pencemaran air tanah perlu diketahui.

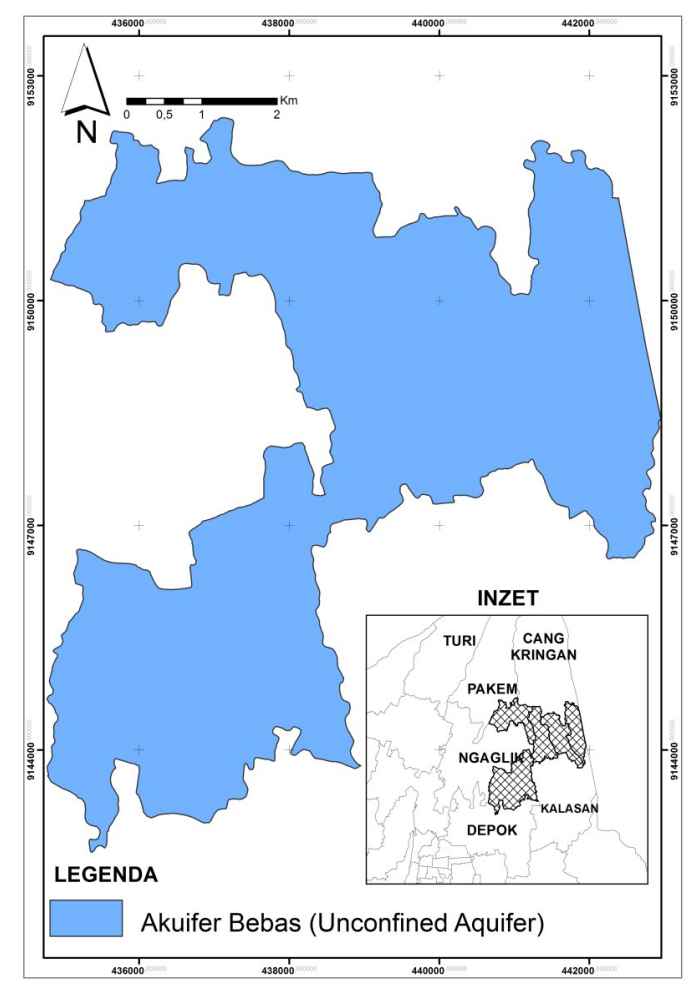

Gambar 3. Peta Sebaran Jenis Akuifer di Daerah Penelitian 
Jurnal Pendidikan Geografi:

Kajian, Teori, dan Praktik dalam Bidang Pendidikan dan Ilmu Geografi

Volume 25, Nomor 1, Jan 2020, Hal 25-38

Tabel 2. Sebaran Vertikan Material di Bawah Permukaan Tanah

\begin{tabular}{lll}
\hline Lokasi Data Bor & Material & Kedalaman (meter) \\
\hline Pakembinangun, & Tanah & 0 \\
Sleman & Pasir kasar dan kerikil halus & 1,5 \\
& Kerikil halus & 5,5 \\
& Pasir kasar dan pasir sedang & 8 \\
& Kerikil halus & 21 \\
& Andesit & 22,5 \\
Tanah & 0 \\
Sleman & Pasir halus dan pasir kasar & 1 \\
& Pasir sedang dan pasir kasar & 32 \\
& Pasir halus & 40 \\
& Pasir sedang dan pasir kasar & 42 \\
& Pasir sedang & 54 \\
& Pasir halus dan pasir kasar & 56 \\
\hline
\end{tabular}

Sumber: PPAB Kementerian Pekerjaan Umum, Kabupaten Sleman

Jenis akuifer merupakan salah satu parameter alami penentu potensi air tanah yang digunakan dalam metode GOD. Berdasarkan kajian geohidrologi, salah satu jenis akuifer adalah akuifer bebas. Akuifer bebas merupakan lapisan akuifer yang hanya dibatasi oleh satu lapisan kedap air. Lapisan kedap air tersebut berlaku sebagai alas akuifer. Muka air tanah merupakan batas atas akuifer bebas dengan zona tidak jenuh air tanah atau dengan kata lain dapat dikatakan bahwa muka air tanah yang terlihat pada sumur galian merupakan indikasi bahwa air sumur tersebut terdapat pada lapisan akuifer bebas. Persebaran akuifer bebas daerah penelitian secara spasial dapat diamati pada Gambar 3.

Zona aerasi atau zona tidak jenuh air tanah merupakan parameter kedua yang dilakukan untuk menentukan potensi pencemaran air tanah. Tabel sebaran vertikal material di bawah permukaan tanah pada daerah penelitian dapat dilihat pada Tabel 2.

Zona atau lapisan ini terletak di bawah permukaan tanah hingga sebelum zona saturasi atau lapisan jenuh air tanah. Hasil identifikasi data bor yang berada di daerah penelitian dan sekitarnya menjelaskan bahwa material zona tidak jenuh air di daerah penelitian didominasi oleh material yang bersifat lepas-lepas (unconsolidated materials). Berdasarkan Tabel 2, dapat dijelaskan bahwa susunan material pada lapisan zona tidak jenuh air tanah didominasi oleh material bersifat lepas- lepas atau tidak terkonsolidasi yang berupa pasir dengan berbagai tingkat sortirannya. Dominasi material pasir tersebut menyebabkan daerah penelitian memiliki kemampuan peresapan air yang baik. Secara spasial, persebaran material pada zona tidak jenuh air di daerah penelitian dapat dilihat pada Gambar 4.

Parameter alami yang juga digunakan untuk menentukan potensi pencemaran air tanah adalah kedalaman muka air tanah. Kedalaman muka air tanah merupakan jarak yang diukur dari permukaan tanah hingga alat ukur menyentuh muka air tanah. Pengukuran 
Jurnal Pendidikan Geografi:

Kajian, Teori, dan Praktik dalam Bidang Pendidikan dan Ilmu Geografi

Volume 25, Nomor 1, Jan 2020, Hal 25-38

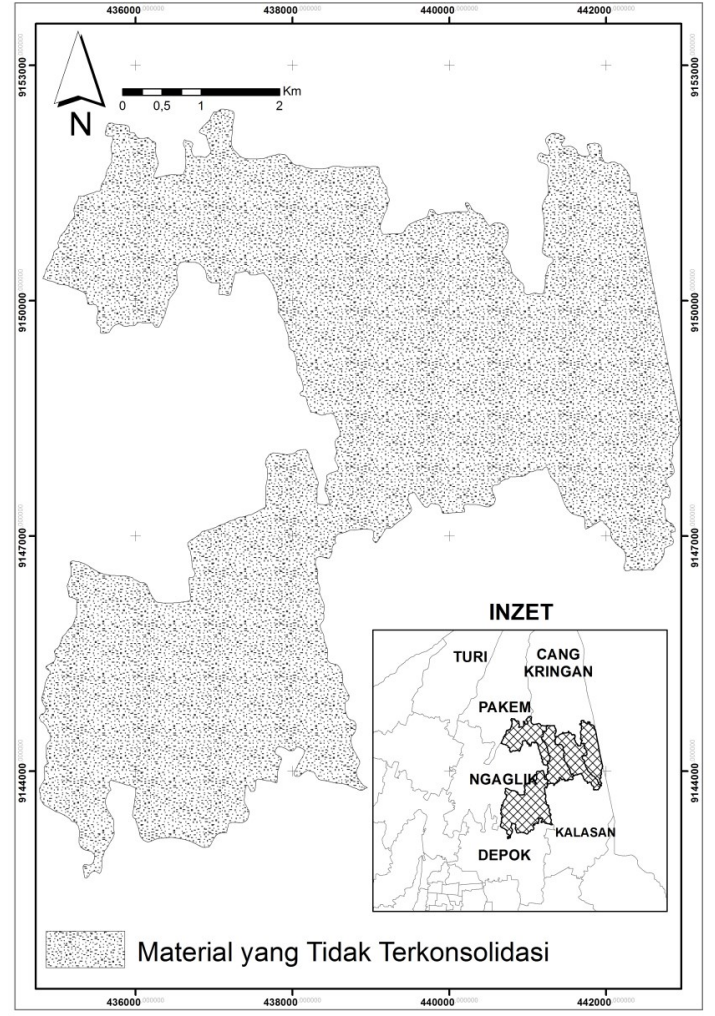

Gambar 4. Peta Sebaran Material Zona Aerasi di Daerah Penelitian

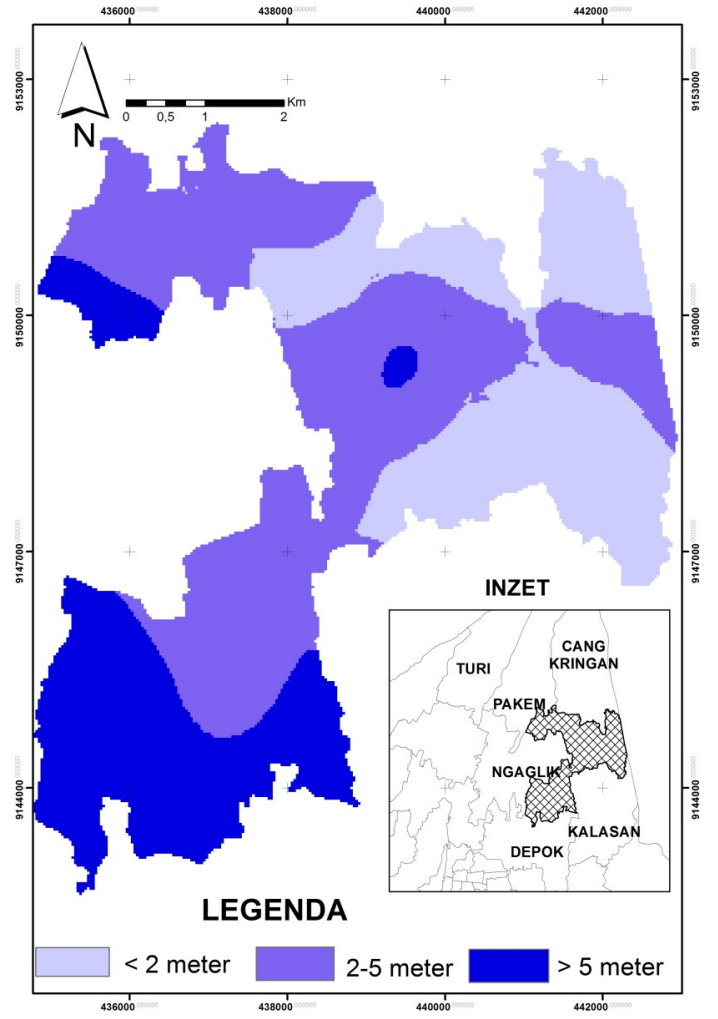

Gambar 5. Peta Sebaran Kedalaman Muka Air tanah di Daerah Penelitian

dilakukan pada sumur-sumur galian yang dibuat penduduk. Sebanyak 75 sampel dikumpulkan untuk memetakan dan mengklasifikasikan kedalaman muka air tanah bebas di daerah penelitian.

Sebaran kedalaman muka air tanah di daerah penelitian dapat dilihat pada Gambar 5. Berdasarkan sejumlah sampel data geospasial, kedalaman muka air tanah bebas di daerah penelitian dapat diklasifikasikan menjadi tiga, yaitu kedalaman 5 hingga 10 meter, kedalaman 2 hingga 5 meter, dan kedalaman kurang dari 2 meter. Pola kedalaman muka air tanah bebas daerah penelitian didominasi oleh kedalaman pada range 2 hingga 5 meter. Keadaan ini menjelaskan bahwa air tanah bebas di daerah penelitian dapat dengan mudah diperoleh dengan membuat sumur galian, karena zona jenuh air tanah berada tidak terlalu jauh dari permukaan tanah.

Kepadatan penduduk merupakan parameter non alami yang digunakan penulis untuk menentukan potensi pencemaran air tanah. Parameter ini digunakan sebagai modifikator metode GOD yang pada awalnya hanya mempertimbangkan kondisik fisik alami. Penulis menganggap bahwa kepadatan penduduk merupakan parameter penting terhadap potensi pencemaran air tanah di suatu wilayah. Berdasarkan anggapan tersebut maka asusmsi ilmiahpun dibangun, yaitu semakin padat penduduk di suatu wilayah maka potensi pencemaran air tanah akan semakin tinggi pula. Mengapa? Karena dengan semakin padatnya penduduk, maka aktivitas- aktivitas harian atau domestik akan semakin intensif. Beragam aktivitas domestik seperti mandi, memasak, mencuci, buang air besar akan memperbanyak produksi limbah yang pada akhirnya berpotensi untuk mencemari air tanah. 
Jurnal Pendidikan Geografi:

Kajian, Teori, dan Praktik dalam Bidang Pendidikan dan Ilmu Geografi

Volume 25, Nomor 1, Jan 2020, Hal 25-38

Tabel 3. Klasifikasi Kepadatan Penduduk

\begin{tabular}{lll}
\hline Kecamatan & Kepadatan $\left(\mathbf{J i w a} / \mathbf{k m}^{2}\right)$ & Kelas \\
\hline Wedomartani & 2514 & Tinggi \\
Umbulmartani & 2076 & Tinggi \\
Widodomartani & 1227 & Rendah \\
Bimomartani & 1651 & Sedang \\
Sindumartani & 1080 & Rendah \\
\hline
\end{tabular}

Sumber: Pengolahan Data, 2019

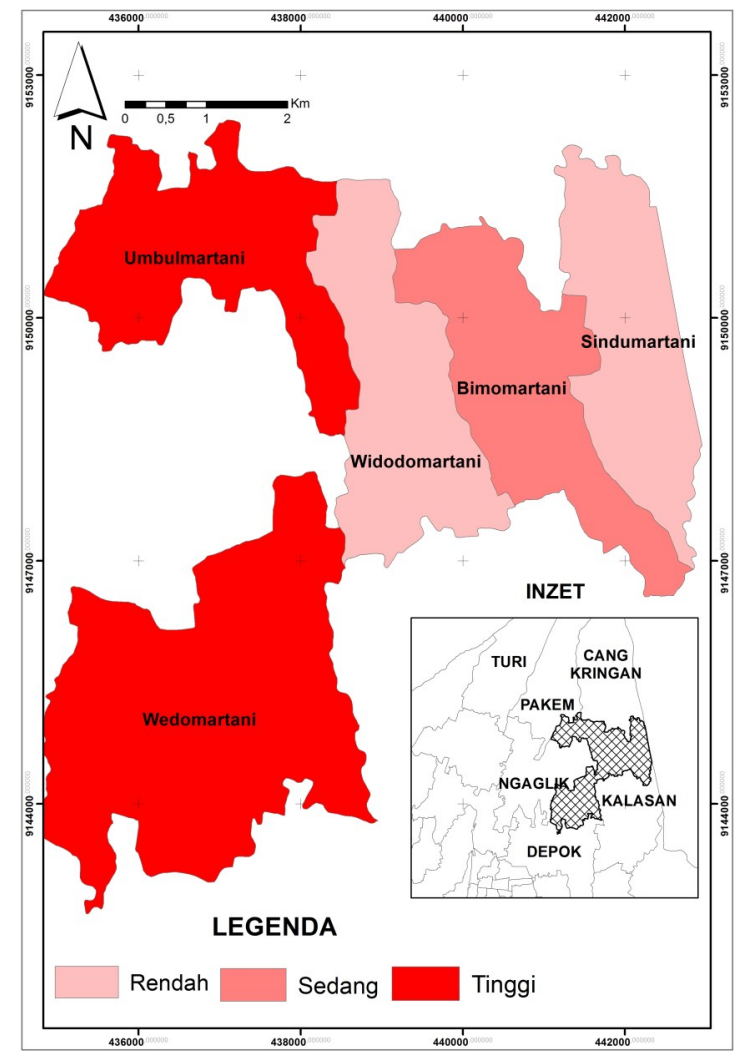

Gambar 6. Peta Sebaran Kepadatan Penduduk di Daerah Penelitian

Data sekunder yang dipublikasikan pada tahun 2018 dari Badan Pusat Statistik tentang Kecamatan Ngemplak dalam Angka digunakan sebagai sumber untuk mengetahui kepadatan penduduk di daerah penelitian. Kepadatan penduduk diklasifikasikan dengan metode Strurgess, khususnya metode interval teratur. Berdasarkan klasifikasi tersebut, daerah penelitian dibedakan menjadi tiga kelas, yaitu kepadatan penduduk tinggi, kepadatan penduduk sedang, dan kepadatan penduduk rendah. Kelas kepadatan penduduk di daerah penelitian dapat dilihat pada Tabel 3 sebagai berikut. Interval kepadatan penduduk tinggi adalah 2038 hingga $2516 \mathrm{jiwa} / \mathrm{km}^{2}$; kepadatan penduduk sedang pada rentang 1559 hingga $2037 \mathrm{jiwa} / \mathrm{km}^{2}$; dan kepadatan penduduk rendah pada rentang 1080 hingga $1558 \mathrm{jiwa} / \mathrm{km}^{2}$.

Secara spasial, persebaran kepadatan penduduk di daerah penelitian dapat dilihat pada Gambar 6. 
Jurnal Pendidikan Geografi:

Kajian, Teori, dan Praktik dalam Bidang Pendidikan dan Ilmu Geografi

Volume 25, Nomor 1, Jan 2020, Hal 25-38

Tabel 4. Klasifikasi Parameter Potensi Pencemaran Air tanah Bebas di Daerah Penelitian

\begin{tabular}{lll}
\hline Parameter GOD & Klasifikasi & Skor \\
\hline Jenis akuifer & Akuifer bebas atau akuifer tidak tertekan & 1 \\
Material penyusun zona & $\begin{array}{l}\text { Material yang bersifat lepas atau tidak terkonsolidasi dengan } \\
\text { aerasi }\end{array}$ & 1 \\
& 5ominasi pasir & 0,8 \\
Kedalaman muka air tanah 10 meter & 2 hingga 5 meter & 0,9 \\
& Kurang dari 2 meter & 1 \\
\hline
\end{tabular}

Sumber: Pengolahan Data, 2019

Berdasarkan Tabel 3 dan Gambar 6, dapat diketahui bahwa dua desa yang menjadi desa terpadat di wilayah administratif Kecamatan Ngemplak adalah Desa Umbulmartani dan Desa Wedomartani, dengan kepadatan masing- masing adalah 2514 jiwa $/ \mathrm{km}^{2}$ dan 2076 jiwa $/ \mathrm{km}^{2}$.

Metode GOD menggunakan tiga parameter kondisi fisik alami suatu wilayah untuk menentukan klasifikasi potensi pencemaran air tanah. Ketiga parameter tersebut adalah jenis akuifer, material zona tidak jenuh air, dan kedalaman muka air tanah. Setiap parameter kemudian diklasifikasikan, sebagai contoh jenis akuifer dibagi menjadi akuifer bebas dan akuifer tertekan, kedalaman muka air tanah dapat dibedakan berdasarkan kelas kedalamannya, dan material zona tidak jenuh air dibagi berdasarkan sifatnya apakah kompak atau tidak kompak, terkonsolidasi atau bersifat lepas- lepas, dan lain sebagainya.

Masing-masing parameter yang telah diklasifikasikan tersebut memiliki skor yang berbeda. Skor yang diberikan akan semakin tinggi jika kondisi fisik alami berkontribusi positif terhadap kemudahan air tanah untuk tercemari, demikian pula sebaliknya, skor akan semakin rendah jika kondisi fisik alami berkontribusi negatif terhadap kemudahan air tanah untuk tercemar. Berdasarkan kajian data primer dan data sekunder yang sebelumnya juga telah dipaparkan, maka rangkuman klasifikasi parameter penentu potensi pencemaran air tanah di daerah penelitian beserta skor yang menyertainya dapat dilhat pada Tabel 4.

Masing-masing parameter yang telah diklasifikasikan dan berbentuk satuan peta tematik tersebut kemudian ditumpangsusunkan. Dalam prosesnya, operasi metaematika yang berupa perkalian digunakan untuk menentukan skor akhir potensi pencemaran dengan metode GOD. Peta potensi pencemaran air tanah di daerah penelitian dapat dilihat Gambar 7.

Berdasarkan Gambar 7, dapat dilihat bahwa jika dikaitkan dengan metode GOD, potensi pencemaran air tanah bebas di daerah penelitian berada dalam klasifikasi sangat tinggi dengan rentang skor akhir mulai dari 0,8 hingga 1 . Dengan kata lain pencemaran air tanah bebas sangat mudah terjadi di daerah penelitian, terutama jika dikaitkan dengan kondisi fisik alami yang berupa jenis akuifer, material penyusun zona aerasi (zona tidak jenuh air tanah), dan kedalaman muka air tanah.

Meskipun klasifikasi potensi air tanah di daerah penelitian seragam, yaitu pada kelas sangat tinggi (extreme), perbedaan kedalaman muka air tanah bebas menyebabkan munculnya variasi skor akhir yang dihasilkan. Variasi tersebut adalah sebagai berikut, pada kelas sangat tinggi dengan skor 0,8 merupakan daerah penelitian yang memiliki kedalaman muka air tanah bebas antara 5 hingga 10 meter; kelas sangat tinggi dengan skor 0,9 merupakan daerah penelitian dengan kedalaman muka air tanah bebas antara 2 


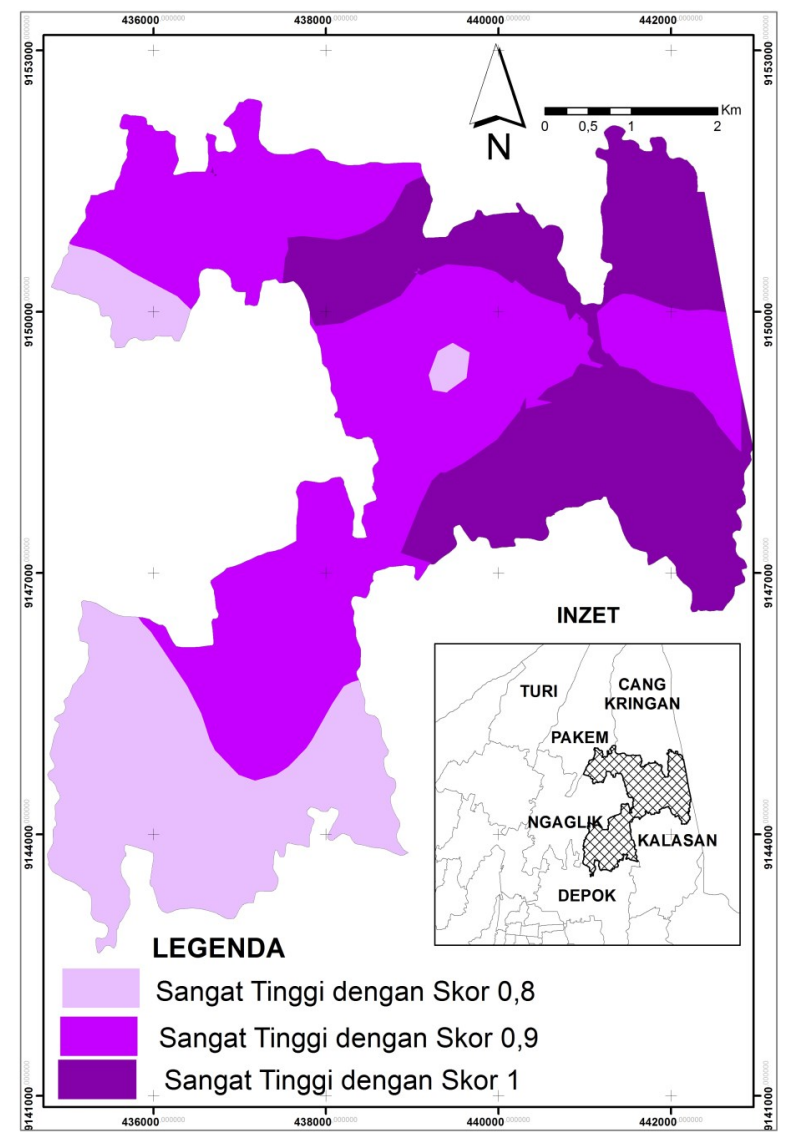

Gambar 7. Peta Potensi Pencemaran Air tanah Bebas Berdasarkan Metode GOD

hingga 5 meter; dan kelas sangat tinggi dengan skor 1 merupakan daerah dengan kedalaman muka air tanah kurang dari 2 meter. Diantara ketiga klasifikasi tersebut, wilayah yang air tanah bebasnya paling mudah tercemar adalah wilayah yang skor akhirnya adalah 1 dengan kedalaman muka air tanah bebas kurang dari 2 meter.

Secara umum, jika dilihat dari parameter fisik alami, air tanah bebas di daerah penelitian sangat mudah mengalami pencemaran. Jenis akuifer bebas yang tersebar di seluruh daerah penelitian memiliki kontribusi positif terhadap potensi pencemaran, terutama jika sumber pencemar berwujud cair. Hal tersebut dapat terjadi karena lapisan akuifer bebas hanya dibatasi oleh satu lapisan kedap air, yaitu pada bagian bawah akuifer, sedangkan pembatas pada bagian atas bukan lapisan kedap air, sehingga polutan yang meresap ke dalam tanah dengan leluasa dapat menjangkau air tanah bebas pada lapisan akuifer bebas. Material zona tidak jenuh air yang tersusun dari material lepas atau tidak terkonsolidasi seperti pasir dengan berbagai ukurannya juga menjadi penyebab tingginya potensi pencemaran air tanah bebas di daerah penelitian. Ruang antar butir atau rongga yang terbentuk dari susunan material yang tidak terkonsolidasi menyebabkan polutan mudah meresap hingga akhirnya mencapai zona jenuh air tanah. Kondisi kedalaman muka air tanah di daerah penelitian secara umum dapat dikatakan dangkal, meskipun terklasifikasi menjadi tiga kelas kedalaman muka air tanah, yaitu kurang dari 2 meter, kedalaman 2 hingga 5 meter, dan kedalaman 5 hingga 10 meter. Kondisi muka air tanah yang dangkal akan mempersingkat waktu polutan untuk mecapai zona jenuh air tanah bebas yang pada akhirnya akan menyebabkan pencemaran. 
Jurnal Pendidikan Geografi:

Kajian, Teori, dan Praktik dalam Bidang Pendidikan dan Ilmu Geografi

Volume 25, Nomor 1, Jan 2020, Hal 25-38

Tabel 5. Cakupan Persentase Luas Wilayah Potensi Pencemaran Air tanah Bebas Berdasarkan Pengembangan Metode GOD di Daerah Penelitian

\begin{tabular}{|c|c|c|c|}
\hline $\begin{array}{l}\text { Klasifikasi Potensi } \\
\text { Pencemaran Air tanah Bebas }\end{array}$ & Cakupan Wilayah & $\begin{array}{l}\text { Luas } \\
\text { Wilayah } \\
\text { (Hektar) }\end{array}$ & $\begin{array}{l}\text { Persentase } \\
\text { Luas } \\
\text { Wilayah } \\
(\%)\end{array}$ \\
\hline Potensi rendah & $\begin{array}{l}\text { Desa Sindumartani dan Desa } \\
\text { Widodomartani }\end{array}$ & 1116,5 & 30,6 \\
\hline Potensi tinggi & $\begin{array}{l}\text { Desa Umbulmartani, Desa Bimomartani, } \\
\text { dan Desa Wedomartani }\end{array}$ & 2531,4 & 69,4 \\
\hline
\end{tabular}

Sumber: Pengolahan Data, 2019

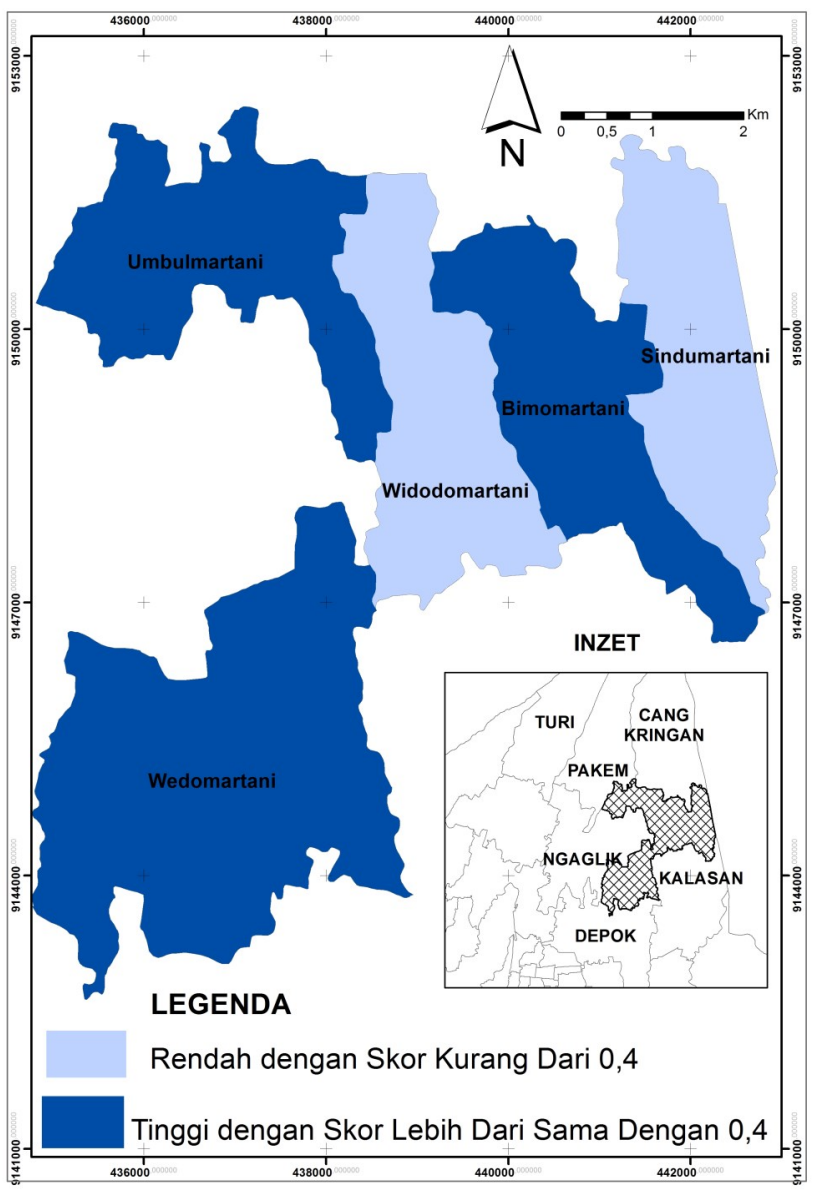

Gambar 8. Peta Potensi Pencemaran Air tanah Bebas Berdasarkan Pengembangan Metode GOD

Potensi pencemaran air tanah bebas yang dihasilkan dengan metode GOD lebih mempertimbangkan kondisi fisik alami, seperti jenis akuifer, kedalaman muka air tanah, dan material penyusun zona tidak jenuh air tanah, sedangkan kondisi non fisik seperti kepadatan penduduk diabaikan. Sehingga dalam penelitian ini, penulis mencoba mengembangkan atau memodifikasi metode GOD tersebut agar parameter selain non fisik dapat dijadikan sebagai pertimbangan dalam penentuan potensi pencemaran air tanah bebas di suatu wilayah.

Parameter non fisik sebagai paramater tambahan (modifikator) dalam penentuan potensi pencemaran air tanah bebas berupa kepadatan penduduk. Parameter kepadatan 
Jurnal Pendidikan Geografi:

Kajian, Teori, dan Praktik dalam Bidang Pendidikan dan Ilmu Geografi

Volume 25, Nomor 1, Jan 2020, Hal 25-38

penduduk tersebut diwujudkan dalam satuan peta tematik kepadatan penduduk di daerah penelitian.Kepadatan penduduk di daerah penelitian diklasifikasikan menjadi tiga kelas kepadatan, yaitu rendah, sedang, dan tinggi. Masing-masing kelas kemudian diberikan skor, yaitu 0,2 pada kelas kepadatan rendah, hingga 0,6 pada kelas kepadatan tinggi. Informasi geospasial potensi pencemaran air tanah bebas di daerah penelitian dengan tambahan parameter kepadatan penduduk dapat dilihat pada Gambar 8.

Berdasarkan Gambar 8, penulis mengklasifikasikan potensi pencemaran air tanah bebas di daerah penelitian menjadi dua kelas, yaitu pada kelas potensi pencemaran rendah dan tinggi. Klasifikasi tersebut berdasarkan skor akhir yang dihasilkan dari operasi perkalian antar skor yang menyertai setiap parameter. Dimana skor akhir yang dihasilkan adalah 0,$2 ; 0,4 ; 0,5$; dan 0,6 . Wilayah yang memiliki skor akhir kurang dari $0,4(<0,4)$ diklasifikaskan ke dalam potensi pencemaran rendah, sedangkan wilayah dengan skor akhir lebih besar dan sama dengan $0,4(\geq 0,4)$ diklasifikasikan dalam potensi pencemaran tinggi. Informasi yang tersaji pada Gambar 8 kemudian dijadikan dasar untuk menentukan sebaran persentase luas wilayah pada masing- masing kelas potensi pencemaran air tanah bebas di daerah penelitian. Informasi tersebut dapat diamati pada Tabel 5.

Penambahan parameter non fisik berupa kepadatan penduduk dalam penentuan potensi pencemaran air tanah bebas menghasilkan informasi yang lebih bervariasi, terutama jika dibandingan dengan hasil potensi pencemaran air tanah bebas pada metode GOD yang hanya mempertimbangkan parameter fisik alami. Berdasarkan informasi pada Gambar 8 dan Tabel 7 dapat diketahui bahwa daerah penelitian didominasi oleh potensi pencemaran air tanah dengan kelas tinggi, dengan cakupan sebesar 69,4\% dari luas seluruh daerah penelitian. Keadaan tersebut dipengaruhi oleh dua hal, pertama adalah kondisi fisik alami daerah penelitian yang secara teori memudahkan interaksi antara sumber pencemar (polutan) dengan air tanah bebas di daerah penelitian. Faktor pengaruh yang kedua adalah kepadatan penduduk. Berdasarkan klasifikasi yang telah dihasilkan, wilayah dengan potensi pencemaran tinggi pada umumnya memiliki kepadatan penduduk yang sedang hingga tinggi, sebagai contoh adalah Desa Umbulmartani, Desa Wedomartani, dan Desa Bimomartani. Potensi pencemaran rendah dengan persentase luas $30,6 \%$ dari luas daerah penelitian tersebar di dua desa yang memiliki kepadatan penduduk rendah, yaitu Desa Sindumartani dan Desa Widodomartani.

Kepadatan penduduk menjadi parameter penting dalam potensi pencemaran air tanah. Berdasarkan hasil penelitian diketahui bahwa kepadatan penduduk berkorelasi positif dengan potensi pencemaran air tanah bebas di daerah penelitian, sehingga dapat diartikan bahwa semakin padat penduduk maka potensi pencemaran air tanah juga semakin tinggi. Limbah domestik atau limbah rumah tangga merupakan contoh sumber pencemar yang dapat mengakibatkan pencemaran air tanah bebas. Limbah domestik atau limbah rumah tangga akan semakin banyak ditemukan pada wilayah dengan penduduk yang padat. Limbah domestik dapat menyebabkan air tanah bebas tercemar oleh unsur kimia dan unsur biologi. Pencemaran air tanah bebas oleh limbah domestik terjadi karena unsur- unsur seperti nitrat, nitrit, bakteri coli (Abdelmadjid dan Omar, 2013; Adji dan Wicaksono, 2012; Hosseini dan Saremi, 2018; Sutardi dkk., 2017; Yorhanita, 2001). Unsur- unsur pencemar akan meresap masuk ke dalam lapisan air tanah bebas dengan mudah, terutama pada wilayah yang memiliki karakteristik alami berupa akuifer bebas, zona aerasi tersusun oleh material lepas, dan kondisi muka air tanah yang dangkal.

Hasil penentuan potensi pencemaran air tanah bebas yang dilakukan dengan menambahkan parameter kepadatan penduduk ini masih memerlukan validasi. Oleh sebab itu, perlu diadakan penelitian yang bertujuan untuk menguji validitas model 
Jurnal Pendidikan Geografi:

Kajian, Teori, dan Praktik dalam Bidang Pendidikan dan Ilmu Geografi

Volume 25, Nomor 1, Jan 2020, Hal 25-38

potensi pencemaran air tanah yang telah dihasilkan. Validasi dapat dilakukan dengan mengambil sampel air tanah sebagai bahan uji labpratorium untuk mengetahui kondisi riil kualitas air tanah di daerah penelitian.

\section{KESIMPULAN}

Potensi pencemaran air tanah bebas di daerah penelitian diketahui dengan dua metode, yaitu metode GOD dan metode yang dihasilkan dari pengembangan metode GOD. Berdasarkan metode GOD, seluruh air tanah bebas di daerah penelitian berada dalam potensi pencemaran sangat tinggi. Variasi potensi pencemaran air tanah diperoleh dengan mengembangkan metode GOD, yaitu menambahkan parameter modifikator yang berupa kepadatan penduduk. Pengembangan metode GOD tersebut menghasilkan dua kelas potensi pencemaran air tanah bebas, yaitu potensi pencemaran rendah dengan cakupan wilayah sebesar 30,6\% dari keseluruhan luas daerah penelitian, dan potensi pencemaran air tanah tinggi dengan cakupan wilayah sebesar 69,4\%. Berdasarkan metode GOD yang telah dikembangkan, diketahui bahwa kepadatan penduduk berkorelasi positif dengan potensi pencemaran air tanah bebas di daerah penelitian, sehingga dapat diartikan bahwa semakin padat penduduk maka potensi pencemaran air tanah juga semakin tinggi. Kepadatan penduduk akan menyebabkan bertambahnya limbah domestik yang berpotensi mencemari air tanah bebas.

\section{DAFTAR RUJUKAN}

Abdelmadjid, B., Omar, S. (2013). Assessment of Gorundwater Pollution by Nitrates Using Intrinsic Vulnerability Methods: A Case Study of The Nil Valley Groundwater Jijel North East Nigeria. African Journal of Environmental Science and Technology, 7(10), 949-960.

Adji, T. N., \& Wicaksono, D. (2012). Analisis Potensi Pencemaran Air tanah Bebas di Kawasan Gumuk Pasir Parangtritis. https://doi.org/10.13140/RG.2.1.4560.4882.

D.Imam Fajri., dkk. (2013). Potensi Air tanah Dangkal Daerah Kecamatan Ngemplak dan Sekitarnya Kabupaten Sleman D.I.Yogyakarta. Prosiding Seminar Nasional Teknik Geologi Universitas Gadjah Mada. Vol.6. Yogyakarta.

Dharoko, A. (2006). Model Arahan Pemanfaatan Lahan untuk Konservasi Sumberdaya Air di Kabupaten Sleman. Jurnal Manusia dan Lingkungan, 13(2), 90-99.

Hastuti, D., Yulianto, T., Putranto. T. (2016). Analisis Kerentanan Air tanah Terhadap Pencemaran di Dataran Aluvial Kota Semarang Menggunakan Metode GOD dengan Memanfaatkan Data Resistivitas dan Data Hidrogeologi. Youngster Physics Journal, 5(4), 277-290.

Hendrayana, H., Vicente, V.A.S. (2013). Cadangan Air tanah Berdasarkan Konfigurasi dan Sistem Akuifer Cekungan Air tanah Sleman Yogyakarta. Prosiding Seminar Nasional Teknik Geologi Universitas Gadjah Mada. Vol.6. Yogyakarta.

Hosseini, M., \& Saremi, A. (2018). Assessment and Estimating Groundwater Vulnerability to Pollution Using a Modified DRASTIC and GODS Models ( Case Study : Malayer Plain of Iran ). Civil Engineering Journal, 4(2), 433-442. Retrieved from http://dx.doi.org/10.28991/cej-0309103.

Khemiri, S., Khnissi, A., Alaya, M. B., Saidi, S., Zargouni, S. (2013). Using GIS for the Comparisson Methods Assessment of Groundwater Vulnerability toPollution in Scenarios of Semi Arid Climate: The Case of Foussana Groundwater in the Central of Tunisia. Journal of Water Resource and Protection, 5, 835-845.

Knouz, N., Bachaoui, E.M., Boudhar, A. (2017). Cartography of Intrinsic Aquifer Vulnerability to Pollution Using GOD Method: Case Study Beni Amir Groundwater, 
Jurnal Pendidikan Geografi:

Kajian, Teori, dan Praktik dalam Bidang Pendidikan dan Ilmu Geografi

Volume 25, Nomor 1, Jan 2020, Hal 25-38

Tadla, Morroco. Journal of Materials and Environmental Sciences, 8(3), 1046-1053.

Nugraha, R.N. (2013). Perubahan Penggunaan Lahan Terhadap Volume Resapan Air tanah di Kecamatan Ngemplak Tahun 1994- 2009. Skripsi. Fakultas Ilmu Sosial Universitas Negeri Yogyakarta. Yogyakarta. $123 \mathrm{hlm}$.

Sutardi,A., Suprayogi, S., Adji, T.N. (2017). Kajian Kualitas Air tanah Bebas antara Sungai Kuning dan Sungai Tepus di Kecamatan Ngemplak Yogyakarta Indoensia. Majalah Geografi Indonesia, 31(1), 31-38.

Oni, T.E., G.O. Omosuyi, A.A. Akinlalu. (2017). Groundwater Vulnerability Assessment Using Hydrogeologic and Geoelectric Layer Susceptibillity Indexing at Igabra Oke Southwestern Nigeria. NRIAG Journal of Astronomy and Geophysics, 6, 452-458.

Vrba, J., Zoporozec, A. (1994). Guidebook on Mapping Groundwater Vulnerability. Hannover: International Association of Hydrogeologists.

Yorhanita, F. (2001). Zonasi Potensi Pencemaran Air Tanah pada Teras Sungai Code Yogyakarta. Manusia Dan Lingkungan, 8(2), 61-69. 